\title{
Past, present and future: music economics at the crossroads
}

\author{
Samuel Cameron ${ }^{1}$
}

Received: 6 July 2015/ Accepted: 7 December 2015/Published online: 16 January 2016

(C) The Author(s) 2016. This article is published with open access at Springerlink.com

\begin{abstract}
This paper contextualises research on the economics of music. The papers considered represent a crossroad in economics music research. One branch is the most heavily explored area of the impact of digital technology on consumption of music. The others comprise one entirely new topic which is crowd-sourced funding of new music recordings. The other topics are extremely old in terms of relevance but very new in terms of there being little prior economic analysis. These are environmental damages from musical activity and the efficiency of belonging to a pop-rock musical ensemble versus being a solo artist.
\end{abstract}

Keywords Crowdfunding $\cdot$ Environment $\cdot$ File-sharing $\cdot$ Band

\section{Introduction}

This essay seeks to provide context to the four articles published in the music special issue of the Journal of Cultural Economics. By now, there has been a significant amount of published academic work by economists in the field of music. A significant earlier survey of the field can be found in Connolly and Krueger (2006). A substantial amount of such work has appeared in the present journal and in other publications by members of the Association for Cultural Economics International. However, the body of work has an extremely skewed distribution. If we do a simple division of economics into demand, supply and pricing, then most of the work on music is on the demand side. Supply side work is very scarce and has generally been about live music chiefly the costs of orchestras (e.g. Lange and

Samuel Cameron

dantalianalysis@yahoo.co.uk

1 University of Bradford, Pemberton Building, Richmond Road, Bradford,

West Yorkshire BD1 7DP, UK 
Luksetich 1993; Schulze and Anselm 1999. Work on pricing of anything in music apart from concert tickets (see, e.g. Connolly and Krueger 2006; Courty and Pagliero 2014; Halcousis and Matthews 2007) on collectibles [see, e.g. Eaton (2007) on guitars, Graddy and Margolis (2011) on violins, Georges and Seçkin (2013) on classical music manuscripts, Cameron and Reynolds (2015) on minidiscs] is relatively infrequent. We may also note a lack of interest in international trade in music which is explored in a descriptive manner in Cameron (2015, Chapter 10) in terms of movement of artists, recorded media and musical equipment across borders.

Early demand work concentrated on aggregate single equation models, specifically focusing on the impact of price and seasonality Burke $(1994,1996)$. There has also been a trickle of problematic attempts to predict success in the music sector using data on chart positions (most usually the US Billboard album or singles charts) or the award of gold records (e.g. Cox et al. 1995; Hamlen 1991, 1994; Strobl and Tucker 2000; Ordanini 2006; Giles 2006, 2007; Dubini and Provera 2008; Hendricks and Sorensen 2009; Moe and Earl 2009 \{Swedish charts\}; Elliott and Simmons 2011 \{UK Charts\}). Some of this work is comparable to a prominent area of research in the study of films as the focus is on skewness in terms of there being a small number of very successful entities and a large number of very unsuccessful ones. Identification of individual factors in the success of works/artists in a way suitable for econometric testing is a major problem. To be fully implemented, this requires some sort of coding of the recorded works, and so far, use of things like key and tempo has not been very insightful. In addition, there is a censorship problem in that charting music is the top slice of the distribution of released music, so comparative data on very unsuccessful music are typically omitted.

Papers on success in terms of performance are sometimes by non-economists such as the work by Gloor (2011) which appeared in the music educators journal and is pinned around Andy Warhol's 'Famous for fifteen minutes dictum' that popular musical stars have often only one major landmark work on which they subsist. Gloor looks at different eras over a long time frame. He specifically identifies the disco era of the late 1970's as possible cause of increased skewness in reward to effort, but his data and methods do not permit any testing of this hypothesis.

The special issue paper by Phillips and Strachan (2016) continues the use of chart data, (Billboard again), but in this instance, the chart data are used to illustrate the potential efficiency of the musical group format rather then being the topic of interest in itself. More recently, the resurgence of talent competitions has raised concerns about the possible extent of market failure due to short-termism in the management of talent and over-focusing on non-musical aspects of performers (Amegashie 2009; Zwaan and ter Bogt 2010).

Of the special issue papers, two deal with little-studied aspects of supply (the sustainability of musical 'groups' or 'bands' versus alternatives such as solo work, financing via crowdsouring), one with the totally neglected market failure problem of the environmental damage from the music sector. The first paper, by Liebowitz (2016), seeks to reach, in so far as possible, a definitive conclusion on the musical 
matter that has most occupied economists in recent times, to wit the impact of copyright infringement, by consumers, on the demand for recorded music.

An alternative review of the impacts of digitisation can be found in Waldfogel (2014). The study of this is a demand issue, although the problems are caused by a supply side revolution. That is, once we begin turning musical recordings into sets of 0's and 1's stored on digital media, it is possible to transfer them across time and space and make infinite numbers of copies at low cost. Formal cost may be zero, but it is best to consider this as 'near-zero' pricing as there are some costs to the user such as impact of use of illegal sites on their own browsing efficiency or indeed the risk and magnitude of prosecution.

\section{The special issue papers in context}

It is perhaps not surprising that downloading, $\mathrm{p} 2 \mathrm{p}$ sharing and now streaming of music have fascinated many economists. Such technical developments challenge the fundamental primacy of the role of prices in economic analysis. If the price of a good falls to (effectively near) zero, we would expect to see collapse of markets and would be faced with an issue about how to allocate resources in the product group if it is deemed to have sufficient net social benefit. We might also expect to see coutervailing activity from the supply side which is where crowdfunding comes in.

The issue of near-zero prices is intrinsically linked to the matter of property rights and thus offers immediate linkage to the well-established law and economics literature. Some economists have taken the radical position that all intellectual property should be free (Boldrin and Levine 2008). We can even find musicians taking a cavalier approach to the traditional business model of selling recorded media as the primary source of income. In May 2015, Wired magazine ran a 'takeover' issue hosted by Skrillex in which the major front cover headline is 'How Data Saved Music' (i.e. the opposite view to the moral panic found in most economics oriented literature). Besides the picture of Skrillex on the front cover, is the bold claim that he does not care if huge numbers of people take his music without payment due to the revenues he can make from other sources derivative of his music/brand.

Although there have been some theoretical papers on this specific topic, more attention has been directed at those seeking to quantify the shift in demand for recorded music media due to disruptive innovation in delivery mechanisms. This is the thorny issue with which Liebowitz (2016) grapples.

Here, we enter the problematic area of classic econometric specification problems and questions of data quality. The econometric problems are very fundamental indeed. Firstly, we are in the arena of counterfactual forecasting. Attributing a fall in demand to a disruptive innovation is difficult because we do not know what demand would have been in its absence.

Historical data also cannot necessarily be treated as representing a market that is in equilibrium prior to the impact of the disruptive innovation. Musical markets have always been subject to profound swings in both aggregate sales and subsectoral (format such as long and short play and by genre) performance. It is entirely 
reasonable that sales may have been above equilibrium in some periods. The shift to dominance of the market by compact discs was characterised by factors that may have pushed demand above its expected level, chiefly aggressive shifts to sales in supermarkets and the tendency to be able to sell reissued old product many times over in new editions.

Music is a discretionary purchase which competes with other leisure goods of which there has been a rapidly growing supply, in large part due to technical innovation. For example, the growth of Internet usage not only increases the scope for near-zero price access to recorded music but it also provides the user with a range of new non-music consumption options (watching videos of cats, social networking and so on) so it is difficult to establish to what extent increased Internet usage per se is the direct cause of decreased physical music sales.

Not all studies in the area are based on aggregate time series data; indeed, several published in the present journal have used individual surveys such as those by Chiang and Assane (2007) based on students at an American university and Nguyen et al.(2014) who survey 2000 French respondents. This paper concludes that free streaming does not reduce cd sales and actually increases live music consumption. Nonetheless, time series data have to be used if we wish to explore the 'disruptive innovation' impacts on recorded music sales. This has lead to sometimes bitter disputes between researchers in the field which Liebowitz seeks to clarify. Liebowitz provides the invaluable service of providing a consistent metric with which to compare different studies. He also combs meticulously through the claims and data sources in key papers which have sought to dispute the size of media sales loss due to digital copyright infringement methods. In particular, he explores the contentiousness of the claims of Oberholzer-Gee and Strumpf $(2007,2009)$ that there is notable empirical evidence of the countereffect, e.g. that file-sharing increases sales of recorded media. This is an entirely possible effect in theoretical terms as file sharers may buy more recorded media out of feelings of responsibility to support artists and also due to increased desire for music from more free samplings. However, whether it outweighs negative effects is a purely empirical matter which is still subject to the various caveats I have outlined above.

Let us now turn to the second special issue paper by Phillips and Strachan (2016). Until the publication by Cameron and Collins (1997), there does not seem to have been any economic work on the collective creative production unit used to generate musical output. This paper specifically dealt with the traditional 'rock/pop' band exemplified by the Beatles. There has been a steady stream of work on symphony orchestras, but this has, as indicated already, been largely about provision. The orchestra is a fixed unit of employees hired to server under a pre-established mode of production. There is also a steady volume of published work on individual composers (exclusively in the field of classical music).

The rock/pop band or group is a flexible organisation which has often consisted of $4 / 5$ people, but there have been many famous trios and duos. Larger ensembles have tended to occur where there is more of a serious crossover into other music genres (such as the band Chicago). The duo form appeared to be a possible dominant mode in the 1980's when synthesisers became cheaper and more powerful', and it also seemed possible that consumers would become happy to 
watch a duo often of primarily a singer and a synthesist. However, after this, there were several fashion waves of the archetypal 'guitar band' format in the late 1980's and 1990's with the 'Grunge' movement from Seattle and the 'Britpop' revival in the UK typified by Blur and Oasis. Electronic dance music continues to generally be made by one or two people in collaboration without an explicit 'band' or 'group' mode of production.

Phillips and Strachan (2016) begin by applying, to the musical group, the questions in the classic 1937 article by Coase which asked why should firms exist at all in the first place. The firm can achieve economies that the individual would not have access to if they executed each contract, necessary to their operations, themselves. Coase's intention was to shift the focus away from the purely technical constraints of production functions which had been emphasised in Marshallian and Pigouvian economics. Attention shifted to the contractual nature of relations. In the case of musical units, all individuals face a menu of options ranging from being a solo performer, a duo, a trio, a traditional $4 / 5$ piece band, a bigger band or even a loosely floating partnership. On the spectrum of looseness, we can have individuals who float between different fixed associations, i.e. belong to more than one band at a time sometimes in different roles.

This fluidity is in contrast to the labour market present in the heyday of the popularity of jazz where there was a clear path that a prominent soloist (usually on a brass instrument) would join the band of an established leader as a sort of apprenticeship. This person would then develop musically and as a 'brand' until they became leaders of their own band. So bands were owned by soloists meaning there is not a clear distinction between 'solo' and 'band' unlike the cases dealt with by Phillips and Strachan. They draw attention to the problem of reward. It is difficult to identify separable marginal products for the inputs even ex post to the production of a song/performance. Long after a unit of production has failed to be artistically and/or commercially successful, people still debate which ingredients were the key to the achievements in the successful period. There is also a question as to whether revenues are actually accruing to the song per se but rather a style of performance (trademark) of which the song is an embodiment. In such a situation of ambivalent marginal revenue product imputation, we have scope for individuals overestimating their own contribution. This could result in the situation (if we could come up with metrics) of the perceived output of the unit adding up to more than the actual output when we sum the individual contributions.

Serendipity also plays a part. We can add this (S) and also authenticity (A) and drugs (D) to the production function. The SAD + augmented production function (Cameron 2015) thus becomes:

$$
\text { (5.2) } \mathrm{Q}=\mathrm{f}(\mathrm{K}, \mathrm{L}, \mathrm{S}, \mathrm{A}, \mathrm{D})
$$

It is unlikely that a typical mathematical form such as the Cobb-Douglas (or more general multiplicative constant elasticity) model would adequately capture the relationships here due to threshold effects, synergy and lexicographic relations which may vary across different production units. 
Serendipity is problematic in an organised market. It is difficult to see how we can guarantee or induce its supply. Authenticity is an interesting element in economic terms as it would, again, seem paradoxical to try to learn or manufacture it. The idea that authenticity is best found outside the stuffy confines of formal linear musical training is frequent from 1940's British Jazz (see Godbolt 2010) to the 1977 Punk 'rebellion' in the UK. It is still a prevalent motif in the case of artists like Seasick Steve.

Drugs constitute a serious issue for the economic analysis of the musical production unit as to what they actually are. Are they some kind of capital, which in conjunction with labour and recording equipment, etc. generate the output? or are they an unfortunate externality of the market which has become ritualised and institutionalised?

Phillips and Strachan do not take into account the role of drugs or serendipity in the differences between group success and that of individuals who have separated from groups. Their chief conclusion is that the majority of musicians in bands will do conspicuously worse when they separate from their successful unit and thus have an incentive to stay in it.

I now turn to the broader context in which crowdsourced musical financing should be placed. What the digital economy and the Internet seems to take away from musicians with one hand, it seems it may offer back with the other. The live music sector and especially festivals have expanded rapidly during the phase of intense concern over copyright infringement-induced revenue loss. This can be due to a number of things, two of which seem to stand out.

One is that the Internet enables much easier low-cost transmission of promotional information for live music. In this instance, unauthorised shared recordings of gigs may be complements rather than substitutes for the actual gigging of the artist. The second factor is income effects. Those who breach copyright save on spending and within a household production model (see Cameron 2015) create substitution effects towards live music as an input in their home musical production function.

The increase in demand for live music has been noted in marketing reports on the buoyancy of the music festival market in the face of major recession (see Larsen and Hussels 2011). We might be tempted to think that live work can fill any income gaps caused by copyright infringement. An econometric study of US time series data by Mortimer et al. (2012) has a graph (Figure 1 on p.4.) showing a perfectly symmetric rise in numbers of concerts performed, plotted against the falling sales of music albums from 2000 to 2003. This choice makes them match almost exactly in slope. However, there are issues of the relative prices and revenues. The detailed econometric work in this study looks at p2p sharing, in the Napster era, and concludes that there is substantial compensation for lost recording revenue in increased performing revenue.

Crowdfunding has appeared as another benefit from the digital world. This applies to all fields not just music and is still generally presented in popular discourse as a revolutionary new thing which has no negative aspects. An example of this in a specialist publication for musicians is Harding (2011). News coverage of crowdfunding has tended to focus on how some David in capitalism has been turned into a Goliath by the power of the people. Musicians are also prone to laud this 
financing method as 'cool' as its putting them in direct contact with fans, thereby cutting out the figure of the capitalist who is often a despised figure in the culture of popular music forms.

The neglected negative aspects (see Micro Mart 2015) have both moral implications and economic efficiency implications. The most obvious negative aspect_-scams/frauds - is likely to be constrained in the music sector as those who provide funds are well placed to determine whether a project is genuine. Failure to reach the target is an economically interesting negative case as there is some deadweight loss of resources as people have given to a project that fails to come to fruition, and effort has been expended for no discernible output. The other chief negative effect of the non-delivery of the product may also be attenuated in many cases as those using crowdfunding are likely to be less prone to squander investment money than their infamous counterparts in the past who have wasted huge sums of record company money (such as The Associates and the Happy Mondays).

Given this, it seems pertinent to consider what factors are most conducive to a crowdfunding campaign being successful. This is the task undertaken in the special issue paper by Mendes-da-Silva et al. (2016), who analyse Brazilian data to look at the connection of the supplier to the funder as a function of distance. That is, greater geographical proximity to the artists leads to higher donations.

This tends to imply that there is a degree of localism in this type of funding, although one has to take into account the specifics of individual nations. The UK, for example, is such a small nation by comparison that funders will tend to be close to project launchers. Contrary cases are also possible where there is a degree of 'glocalism' that a community far removed from the location of the artist exhibits an intense loyalty to the project. This is an ideal case for the crowdfunding approach to be successful.

As an example of this, we may consider the recording return of Australian ensemble 'The Apartments' (essentially one man Peter Walsh with friends) who ended a very long hiatus with a new album 'No Spell No Madrigal' in 2015. It is completely unsurprising that this venture has seen resort to crowdfunding given the cult status of the artist which attracts small numbers of very fervent fans. However, it has been funded not in Australia or the UK or the USA but on the French website microcultures (see http://www.microcultures.fr/fr/project/view/no-song-no-spellno-madrigal). Accessing this site [on 7 May 2015] showed that a target of 10,000 Euro had been passed to a total of 13,714 Euros. Funds came from 454 'microcultivateurs' giving an average donation of 30.21 Euros which is maybe about 1.6-2x what it would cost simply to buy a basic cd on amazon via old-fashioned production methods. Each individual donor name is listed as part of the return.

It is perhaps slightly awkward to actually call this investment as the funders are receiving mainly consumer goods where any excess they pay may not even necessarily be an act of altruism even as the excess may correspond to an 'emotional premium' of involvement and recognition. This highlights that the method may actually tend in the long run to be a marketing tool in a competitive environment rather than being a welfare improving market failure remedy.

Despite the greeting of this approach as novel, it has precedents (e.g. the Marillion album, Anoraknophobia in 2001), but these were isolated with no 
dedicated vehicle to deliver and manage this process. Some concrete examples, which show the marketing nature of the exercise from the kickstarter.com campaign of virtuoso jazz-rock ensemble Led Bib in 2013, are shown in Cameron (2015, Table 5.2, p.94). This raised $£ 10,221$ from 151 backers, an average of just below $£ 7$ per backer. Information on their backers is necessarily incomplete, but where it is given, it seems most people backed ONLY this campaign. The exception being a gentleman who backed 64 campaigns in total, of which only one was musical.

This Led Bib campaign highlights the possible inefficiency and inconsistencies of the popularisation of the method. The band bring out the archetypal explanation that it was a 'cool way' to fund the album, and it is really putting them in touch with their fans. Yet, the call is actually in conjunction with a record label, and many of the pledges are actually just advance purchases of standard goods. In this case, the more personal and unique type items did not get taken up to much degree.

There also seems to be a terribly over complex 'buffet' of options here. There are numerous combination offers comprising such things as a pot of the members' favourite humus, music lessons from members, having cover versions played in concert and so on. Given the outcomes, one might suggest that it might be more efficient to simply use a range of special T-shirts, for sale with a few other items. It is perhaps slightly specious to claim that these smallish sums of money are actually needed to fund recording of the work identified. They seem much more to be part of a continuous product placement campaign. The same could be said of the Apartments campaign.

If academic papers on the mode of musical production and on crowdfunding in music are rare, then those on the environmental impact of the music industry are even rarer. In their special issue contribution, Connolly et al. (2016) contribute a welcome pioneering work to this topic. They evaluate only the impact of carbon emissions from fan travel which puts a lower limit on the magnitude of musical environmental damage.

Musical production and consumption has always been a source of great potential resource waste and environmental damage. Manufacture of musical equipment is a source of environmental damage, but it is subject to the same regulations as other electrical equipment: for example, the EU solder directive required the withdrawal of some electronic musical equipment.

Historically, the proscription of the use of ivory-coated wooden piano keys and its replacement with plastic might be considered an example of responsible capitalism. However, price in any case was a powerful driver of change in this area. According to Baird (1996, p.183), by the mid-nineteenth century, manufacturers were developing many cheaper alternatives to ivory coatings.

Currently, manufacturers of musical equipment do not seem to seek to portray themselves in any particularly favourable light as custodians of the environment. The only instance I am aware of is the digital pianos manufactured by Kawai who became the first piano manufacturers, in 1997, to receive ISO 14001 certification for excellence in environmental management. In 1998, they gained a second ISO 14001 certification for exceptional achievement in reforestation, energy conservation, waste reduction and natural resource preservation at the Upright Piano Factory. In 1999, ISO 14001 certification was awarded to their Marchen Digital Piano Facility. 
On the non-corporate alternative fringe of equipment making, we can find people who are effectively recycling casings/housings and components (on craft websites such as Etsy or via ebay selling). More ambitiously, the thriving community of 'circuitbenders' repurpose obsolete equipment (especially instruments which veer towards the 'toy' category such as Yamaha and Casio teaching-oriented keyboards) by opening it up and modifying the internal circuitry. Such activity not only adds value to such items but also slows down the accumulating heap of electronic junk which might even, in some cases, cost money to dispose of ethically.

In terms of musical media, the production of vinyl and the packaging of cd's in plastic jewel cases were both intensive in the use of scarce resources. The world shortage of vinyl in the early 1970's lead to the temporary production of thin bendable long playing 33 1/3 rpm records (lps) (most notably on the RCA label for such artists as David Bowie), and although some independent releases and cd singles were distributed in the 'digipak' format (cardboard folder with plastic tray), the vast bulk of cds were sold in the plastic box jewel case format which is very environmentally wasteful.

Digital distribution has tremendous environmental benefits as we no longer need to use up scarce resources to produce playable media or transport them round the world or indeed policing counterfeit physical production. However, live performance represents a field of potentially rampant growth in environmental damage due to the distances travelled, the amount of equipment carried and the impracticability of there being a welfare optimum in destination management. The carbon footprint of many musicians will vastly exceed that of typical everyday workers who fly mainly on holiday and commute mostly to work and back.

The idea that musicians might care about this and seek to do something about it would seem to fall under the field of corporate social responsibility (CSR) on which there is a great deal of academic writing. However, the artists are not typically themselves the corporations but their employees or contractees. As Connolly et al. (2016) note, many artists, such as Michael Jackson, have espoused environmental concern in their works without doing much to address the issue. Indeed, in the case of benefit concerts, we might actually witness supposedly altruistic activity which has a damaging environmental effect due to the carbon footprint of the performers.

CSR faces the hard economic problem that reducing environmental damage is unwelcome to shareholders/owners if it eats into profits. Performers themselves may chose to take an effective wage reduction instead by using less harmful travel methods (e.g. Radiohead in their campaign tried to travel by sea if possible instead of air). One might argue that profits do not have to be traded off if there are unexploited efficiency gains, e.g. by better coordination of the route of tours and more use of prolonged stays in one venue. However, there are serious barriers here as the route used on a tour is partly determined by other tours with cross-performer coordination being difficult. Also, as identified by Connolly et al. (2016), the strategy of consolidating more performances in one location may reduce the carbon footprint of the musicians, but it shifts that of consumers up as there is more travelling to the venue.

Conventional economic tools can be used to value the environmental impact of music (as is done in the paper provided here) and also to devise optimal policy 
interventions. Traditional Pigouvian welfare economics might suggest that musicians or their host corporations could be subject to negative externality internalising taxes levied in optimal proportion to the harm caused. Or, we could have a permitbased approach. If the agents concerned are making some degree of supernormal profits (and are not straightforward profit maximisers), then it is possible that this may not reduce their output. They may of course be stimulated to engage in input substitution in response to interventionist welfare measures.

\section{Future Prospect}

It is clear that there is scope for interesting future theoretical and empirical research in the field of economics of music. To some extent, this requires grappling with issues that still trouble the core of mainstream economics. These are chiefly producing a wider model of consumer behaviour and coming to terms with the shift to a digital and knowledge-based economy rather than one so heavily based on physical production.

Open Access This article is distributed under the terms of the Creative Commons Attribution 4.0 International License (http://creativecommons.org/licenses/by/4.0/), which permits unrestricted use, distribution, and reproduction in any medium, provided you give appropriate credit to the original author(s) and the source, provide a link to the Creative Commons license, and indicate if changes were made.

\section{References}

Amegashie, J. A. (2009). American Idol: Should it be a singing contest or a popularity contest? Journal of Cultural Economics, 33(4), 265-278.

Anon. 2015. The Dangers of Crowdfunding. Micro Mart 1361 pp.22-24 (author name is given as Sarah with second name missing).

Baird, P. F. (1996). Ivories. In R. Palmieri (Ed.), Encylopedia of the Piano (p. 183). New York and London: Garland Reference Library of the Humanities. Garland Publishing.

Boldrin, M., \& Levine, D. K. (2008). Against intellectual monopoly. Cambridge: Cambridge University Press.

Burke, A. E. (1994). The Demand for Vinyl L.P.s 1975-1988. Journal of Cultural Economics, 18(1), 41-64.

Burke, A. E. (1996). The dynamics of product differentiation in the British record industry. Journal of Cultural Economics, 20(2), 145-164.

Cameron, S. (2015). Music in the marketplace : A social economics approach. London: Routledge.

Cameron, S., \& Collins, A. (1997). Transaction costs and partnerships: The case of rock bands. Journal of Economic Behavior and Organisation, 32(2), 171-183.

Cameron, S., \& Reynolds, M. (2015). The value of collecting a particular musical artist: the case of MiniDiscs. Briefing Notes in Economics, forthcoming.

Chiang, E. P., \& Assane, D. (2007). Determinants of music copyright violation on the university campus. Journal of Cultural Economics, 31(3), 187-204.

Coase, R. H. (1937). The nature of the firm. Economica, 4, 386-405.

Connolly, M., Dupras, J., \& Seguin, C. (2016), An economic perspective on rock concerts and climate change: The decision to compensate emissions using carbon offsets, Journal of Cultural Economics, 40(1), doi:10.1007/s10824-015-9265-2.

Connolly, M., \& Krueger, A. B. (2006). Rockonomics: The economics of popular music. In Throsby D. GinsburghV (Ed.), Handbook of the economics of art and culture (Vol. 1, pp. 667-719). Elsevier: North-Holland. 
Courty, P., \& Pagliero, M. (2014). The pricing of art and the art of pricing: Pricing styles in the concert industry. In V. Ginsburgh \& D. Throsby (Eds.), Handbook of the economics of art and culture (Vol. 2, pp. 299-356). Elsevier: North-Holland.

Cox, R. A. K., Felton, J. M., \& Chung, K. H. (1995). The concentration of commercial success in popular music: An analysis of the distribution of gold records. Journal of Cultural Economics, 19(4), 333-340.

Dubini, P., \& Provera, B. (2008). Chart success and innovation in the music industry: Does organizational form matter? Journal of Media Business Studies, 5(1), 41-65.

Eaton, D. H. (2007). The impact of reputation, timing and source on auction outcomes. The B.E. Journal of Economic Analysis and Policy. 7(1).

Elliott, C., \& Simmons, R. (2011). Factors determining UK album success. Applied Economics, 43(30), 4699-4706.

Georges, P., \& Seçkin, A. (2013). Black notes and white noise: A hedonic approach to auction prices of classical music manuscripts. Journal of Cultural Economics, 37(1), 33-60.

Giles, D. E. (2006). Superstardom in the U.S. popular music industry. Economics Letters, 92(1), 68-74.

Giles, D. E. (2007). Survival of the Hippest: Life at the top of the hot 100. Applied Economics, 39(15), $1877-1887$.

Gloor, S. (2011). Just How Long Is Your "Fifteen Minutes?" An empirical analysis of artists' time on the popular charts. Music and Entertainment Industry Educators Association Journal, 11(1), 61-82.

Godbolt, J. (2010). A history of jazz in Britain: 1919-1940. London: Northway Productions.

Graddy, K., \& Margolis, P. E. (2011). Fiddling with value: Violins as an Investment. Economic Inquiry, 49(4), 1083-1097.

Halcousis, D., \& Matthews, T. (2007). eBay Auctions for Third Eye Blind concert tickets. Journal of Cultural Economics, 31(1), 65-78.

Hamlen, W. A, Jr. (1991). Superstardom in popular music: Empirical evidence. The Review of Economics and Statistics, 73(4), 729-733.

Hamlen, W. A, Jr. (1994). Variety and superstardom in popular music. Economic Inquiry, 32(3), 395-406.

Harding, J. G. (2011). Crowd control. Digital Marketing and Crowd Funding, Sound on Sound, 26(9), $168-172$.

Hendricks, K., \& Sorensen, A. (2009). Information and the skewness of music sales. Journal of Political Economy, 117(2), 324-369.

Lange, M. D., \& Luksetich, W. A. (1993). The cost of producing symphony orchestra services. Journal of Cultural Economics, 17(2), 1-15.

Larsen, G., \& Hussels, S. (2011). The significance of commercial music festivals. In S. Cameron (Ed.), Handbook of the economics of leisure. Cheltenham: Edward Elgar.

Liebowitz, S. (2016). How much of the decline in sound recording sales is due to file-Sharing? Journal of Cultural Economics, 40(1), doi:10.1007/s10824-014-9233-2.

Mendes-da-Silva, W.,Conte, B.S.,Gattaz, C.C., Francisco, E.R. \& Rossoni, L. (2016). The impact of geography on financing music production via crowdfunding in Brazil, Journal of Cultural Economics, 40(1), doi:10.1007/s10824-015-9248-3.

Moe, A. G., \& Earl, P. E. (2009). Bandwagon and reputation effects in the popular music charts. Queensland: University of Queensland.

Mortimer, J., Nosko, C., \& Sorenson, A. (2012). Supply responses to digital distribution: recorded music and live performances. Information Economics and Policy, 24, 3-14.

Nguyen, G. D., Dejean, S., \& Moreau, F. (2014). On the complementarity between online and offline music consumption: the case of free streaming. Journal of Cultural Economics, 38(4), 315-330.

Oberholzer-Gee, F., \& Strumpf, K. (2007). The effect of file sharing on record sales: An empirical analysis. Journal of Political Economy, 115(1), 1-42.

Oberholzer-Gee, F., \& Strumpf, K. (2009). File- sharing and copyright. In L. Joshua \& S. Scott (Eds.), Innovation policy and the economy, 10 (pp. 19-55). Chicago: University of Chicago Press.

Ordanini, A. (2006). Selection models in the music industry: How a prior independent experience may affect chart success. Journal of Cultural Economics, 30(3), 183-200.

Phillips, R., \& Strachan, I. C. (2016). Breaking up is hard to do: The resilience of the rock group as an organizational form for creating music. Journal of Cultural Economics, 40(1), doi:10.1007/s10824014-9226-1.

Schulze, G. G., \& Anselm, R. (1999). Public orchestra funding in Germany-An empirical investigation. Journal of Cultural Economics, 22(4), 227-247. 
Strobl, E., \& Tucker, C. (2000). The dynamics of chart success in the U.K. pre-recorded popular music industry. Journal of Cultural Economics, 24(2), 113-134.

Waldfogel, J. (2014). Digitization, copyright, and the flow of new music products. In V. Ginsburgh \& D. Throsby (Eds.), Handbook of the Economics of Art and Culture (Vol. 2, pp. 277-298). Elsevier: North-Holland.

Wired Magazine. (2015). Skrillex Takeover Issue, May.

Zwaan, K., \& ter Bogt, T. F. M. (2010). From zero to hero? An exploratory study of the predictors of success in the dutch idols competition. Journal of Popular Music and Society, 33(3), 319-337. 